This is a postprint version of the following published document:

M.J. Martínez-Morlanes, A.M. Martos, A. Várez, B. Levenfeld. Synthesis and characterization of novel hybrid polysulfone/silica membranes doped with phosphomolybdic acid for fuel cell applications. Journal of Membrane Science, 492 (2015), pp 371-379

(c) 2015 Elsevier B.V. All rights reserved.

DOI: $\underline{10.1016 / \mathrm{j} . \mathrm{memsci} .2015 .05 .031}$ 


\title{
Synthesis and characterization of novel hybrid polysulfone/silica membranes doped with phosphomolybdic acid for fuel cell applications
}

\author{
M.J. Martínez-Morlanes*, A.M. Martos, A. Várez, B. Levenfeld \\ Department of Materials Science and Engineering and Chemical Engineering, Universidad Carlos III de Madrid, Avda. Universidad, 30, E-28911 Leganés, Spain
}

Keywords:

Proton-exchange membrane fuel cell

Polysulfone

Silicon oxide

Heteropolyacid

Electrochemical impedance spectroscopy

\begin{abstract}
A B S T R A C T
Novel proton conducting composite membranes based on sulfonated polysulfone ( $\mathrm{sPSU}) / \mathrm{SiO}_{2}$ doped with phosphomolybdic acid (PMoA) were synthesized, and their proton conductivity in acid solutions was evaluated. The hybrid membranes were prepared by casting and the characterization by scanning electron microscopy (SEM), Fourier transform infrared (FTIR) and X ray diffraction (XRD) confirmed the presence of the inorganic charges into the polymer. Thermal properties and proton conductivity were also studied by means of thermogravimetric analysis (TGA) and electrochemical impedance spectro scopy (EIS), respectively. The incorporation of the inorganic particles modified the thermal and mechanical properties of the sPSU as well as its proton conductivity. Taking into account that a compromise between these properties is necessary, the hybrid membrane with $2 \% \mathrm{SiO}_{2}$ and $20 \% \mathrm{PMoA}$ seems to be a promising candidate for its application in proton exchange membrane in fuel cells (PEMFCs) operated at high temperatures.
\end{abstract}

\section{Introduction}

Nowadays, clean energy technologies play an important role in overcoming fossil fuel exhaustion and global pollution. Among these technologies, fuel cells are electrochemical energy systems that convert energy from a chemical reaction into electrical energy without emitting pollutants. In particular, the polymer fuel cells based on proton exchange membranes (PEMFCs) are of great importance in the automotive field because of its higher energy efficiency and no emission compared to the combustion engines [1]. Currently, the most commonly used polymer electrolyte in PEMFC is based on expensive perfluorinated membranes, such as Nafion ${ }^{\circledR}$, which present high proton conductivity, good mechan ical strength and excellent stability. However, these membranes show several drawbacks since to ensure good proton conduction they must be fully hydrated, limiting their working temperature range below $80{ }^{\circ} \mathrm{C}$ and $100 \%$ relative humidity [2,3]. Moreover, this type of membrane exhibits high methanol permeability and high

Abbreviations: sPSU, Sulfonated polysulfone; PWA, Phosphotungstic acid; PMoA, Phosphomolybdic acid; SEM, Scanning electron microscopy; FTIR, Fourier transform infrared; XRD, X-ray diffraction; TGA, Thermogravimetric analysis; EIS Impedance spectroscopy technique; PEMFC, Proton-exchange membrane fuel cells PSU, Polysulfone; $\sigma_{m}$, Membrane ionic conductivity; $r_{m}$, Membrane ionic resistivity

* Corresponding author. Tel: +34916249500.

E-mail address: mariajma@ing.uc3m.es (M.J. Martínez-Morlanes). cost of production, which limits its further application and future commercialization.

These limitations have led to research and develop different polymers as promising alternatives to improve fuel cell perfor mance of the current perfluorosulfonic membranes. One research line involves the sulfonation of aromatic polymers with non perfluorinated backbone such as polyaryl ether ketone [4], poly styrene [5] as well as polybenzimidazoles [6]. Among these polyaromatic materials, polysulfone (PSU) is a commercially avail able polymer and well known for its excellent mechanical, thermal and chemical stability [7]. Hybrid organic inorganic nanocompo sites have gained considerable attention because present improved properties such as swelling capacity, water retention or operating temperature, while maintaining mechanical proper ties [8 10]. In this line, there are several studies that reflect the improvement of performance of several polymers due to the incorporation of inorganic particles such as $\mathrm{SiO}_{2}$ [11], $\mathrm{TiO}_{2}$ [12] or zeolites [13]. Also, another inorganic fillers such as heteropo lyacids like phosphotungstic (PWA), phosphomolybdic (PMoA), silicotungstic (SiWA) and silicomolybdic (SiMoA) acids related to the well known Keggin structure, have recently received most attention due to their good proton conductivities [14 17]. How ever, it is well known that heteropolyacids itself are water soluble and may be easily extracted during the operation of fuel cell, leading to the instability of the composite membranes. For this reason, the retention of heteropolyacid into polymer matrix 
appears as one of the most challenge in preparing heteropolyacid containing membranes. For this purpose, inorganic particles have been incorporated together these materials to immobilize them inside a polymer matrix [18]. Thus, the incorporation of $\mathrm{SiO}_{2}$ nanoparticles showed that it is effective to reduce PWA leaching in sulfonated polysulfone nanocomposites membranes [19]. The aim of this work was the evaluation of novel proton conducting composite electrolyte based on hybrid polysulfone $/ \mathrm{SiO}_{2}$ mem branes doped with PMoA as possible alternative for current used PEMFC. Furthermore, sPSU/SiO ${ }_{2}$ membranes containing different amounts of $\mathrm{SiO}_{2}$, were also prepared for comparation.

\section{Experimental}

\subsection{Materials}

The polymer used in the study was polysulfone Udel (PSU) with $M n=22,000$. The solvents were trimethylsilyl chlorosulfonate (TMSCS, 99\%), 1,2 dichloroethane (DCE) and N,N dimethylaceta mide (DMAc). For the preparation of composites two inorganic compounds were used, pyrogenic silica (fumed silica, 99.8\%) with an average particle size of $11 \mathrm{~nm}$ and surface area of $255 \pm 15 \mathrm{~m}^{2}$ / $\mathrm{g}$, and commercial phosphomolybdic acid $\left(\mathrm{H}_{3} \mathrm{PMo}_{12} \mathrm{O}_{40} \cdot x \mathrm{H}_{2} \mathrm{O}\right.$, PMoA). All of these reagents were purchased from Sigma Aldrich. Sulfonated product purification was carried out by adding ethanol (Panreac).

\subsection{Sulfonation of polysulfone}

Firstly, the sulfonation process was carried out in anhydrous conditions following the method described by Chao et al. [20]. Thus, a solution of polysulfone in DCE was prepared and purged with nitrogen for one hour. Then, a solution containing the sulfonating agent (TMSCS) and DCE was slowly added drop by drop under magnetic stirring. The resulting mixture was addition ally stirred for $24 \mathrm{~h}$ at room temperature. Once the sulfonation process was completed, the product obtained was poured into ethanol. Finally, the precipitated polymer was filtered and washed with distilled water up to neutral $\mathrm{pH}$.

\subsection{Composite membrane preparation}

All membranes were prepared by casting procedure. A solution consisting of $5 \mathrm{wt} \%$ of sPSU in DMAc was stirred for $2 \mathrm{~h}$ at room temperature and subsequently was filtered. For the preparation of sPSU/SiO ${ }_{2}$ membranes, different amounts of $\mathrm{SiO}_{2}$ nanoparticles $(0.5,1,2,4$ and $6 \mathrm{wt} \%)$ were added and the resulting mixture was stirred for $1 \mathrm{~h}$ at $60^{\circ} \mathrm{C}$. Afterward, the solutions were placed in an ultrasonic bath at $60{ }^{\circ} \mathrm{C}$ for $1 \mathrm{~h}$ and finally they were magnetically stirred for an additional $1 \mathrm{~h}$ at room temperature. Subsequently, the solutions were filtered, added to a Petri dish and heated in order to remove the solvent.

On the other hand, for some $\mathrm{SiO}_{2}$ doped membranes (2 and $4 \mathrm{wt} \%$ ), the effect of the addition of the heteropolyacid was studied. In this case, different amounts of PMoA (10 and $20 \mathrm{wt} \%$ ) were dispersed with $\mathrm{SiO}_{2}$ in water. The resulting suspension was dried at room temperature and the obtained solid was crushed using an agate mortar with the aim to obtain a fine powder. After that, the preparation of $\mathrm{sPSU} / \mathrm{SiO}_{2} / \mathrm{PMoA}$ composite membranes was carried out by the same mixing and thermal procedure used in preparation of sPSU/SiO ${ }_{2}$ membranes aforementioned. As result, thick membranes between 80 and 140 microns were obtained.

\subsection{Methods}

\subsection{1. ${ }^{1} \mathrm{H}$ NMR analysis}

The sulfonation degree of sPSU was estimated by means of liquid ${ }^{1} \mathrm{H}$ NMR [21]. The analysis was performed on a Bruker Avance DPX $300 \mathrm{MHz}$ spectrometer using dimethylsulfoxide (DMSO $d_{6}$ ) as the solvent and tetramethylsilane (TMS) as internal reference.

\subsubsection{SEM}

The morphology of prepared membranes was analyzed with a Philips XL30 scanning electron microscope operating at $15 \mathrm{kV}$ and equipped with a backscattered electron detector (BSE) and an energy dispersive analyzer (EDAX 4i). In order to examine the cross sections, the membrane samples were fractured cryogeni cally by immersion into liquid nitrogen and then coated with gold.

\subsubsection{Infrared spectroscopy}

Infrared characterization was performed using a Perkin Elmer Spectrum GX Instrument (resolution $4 \mathrm{~cm}^{1}$ ) in the range of $4000400 \mathrm{~cm}^{1}$. The infrared spectra of $\mathrm{SiO}_{2}$ and $\mathrm{PMoA}$ powder were recorded in $\mathrm{KBr}$ pellets and composites membranes slices of about 50 microns of thickness were used for the analysis.

\subsection{4. $X$ ray diffraction}

$\mathrm{X}$ ray diffraction (XRD) patterns were recorded on a Philips $\mathrm{X}$ 'Pert diffractometer equipped with a $\mathrm{CuK} \alpha$ radiation source. This instrument has a $(\theta / 2 \theta)$ Bragg Brentano geometry and is equipped with a curved graphite monochromator. The $2 \theta$ range analyzed was $555^{\circ}$ with a step scan of $0.02^{\circ}$ and a counting time of $2.8 \mathrm{~s}$ per step. Finally, the experiments were carried out at an excitation voltage of $40 \mathrm{kV}$ and a current of $40 \mathrm{~mA}$.

\subsubsection{PMoA extraction}

To evaluate the ability of silica nanoparticles to reduce the leaching of heteropolyacid in water, we have estimated the extraction of PMoA by means of UV vis spectroscopy. The study was carried out in a Jasco V 650 UV vis spectrophotometer. The $\mathrm{sPSU} / \mathrm{SiO}_{2} / \mathrm{PMoA}$ composites membranes were immersed in deio nized water at room temperature for $72 \mathrm{~h}$. After that, the solvent with extracted PMoA was placed into a quartz cell and then measured at $253 \mathrm{~nm}$, which correspond to the maximum absorp tion of the studied heteropolyacid. Thus, the PMoA extraction (\%) was determined by using the following equation [19]:

$\mathrm{PMoA}_{\text {extraction }}(\%)=\frac{C \times V}{M_{\mathrm{PMoA}}} \times 100$

where $C$ is the extracted PMoA concentration obtained from the concentration absorption graph.

\subsubsection{Water uptake}

Given that the water content affects the proton conductivity and mechanical properties of the membranes, the water uptake percentage was determined. For this purpose, the membranes were dried in a vacuum oven at $60{ }^{\circ} \mathrm{C}$ for $24 \mathrm{~h}$ until constant weight. Each dried membrane was subsequently weighed ( $\left.W_{\text {dry }}\right)$ and soaked in distilled water at room temperature for $72 \mathrm{~h}$. After that, the membranes were taken out and immediately weighed $\left(W_{\text {wet }}\right)$ after removing the surface water. Water uptake was calculated using the following equation:

$W_{\text {uptake }}(\%)=\frac{W_{\text {wet }} W_{\text {dry }}}{W_{\text {dry }}} \times 100$

where $W_{\text {wet }}$ and $W_{\text {dry }}$ are the weights of the wet and dry membrane, respectively. 
In case of the $\mathrm{sPSU} / \mathrm{SiO}_{2} / \mathrm{HPA}$ membranes, the measure of the water uptake values was calculated taking into account the loss of HPA produced during the immersion in water. Thus, the loss mass of this component was considered in the obtained $W_{\text {dry }}$ values.

\subsubsection{Thermogravimetric analysis}

Thermogravimetric experiments were performed in a Perkin Elmer TGA1 analyzer from $30^{\circ} \mathrm{C}$ to $900{ }^{\circ} \mathrm{C}$ at a heating rate of $10^{\circ} \mathrm{C} / \mathrm{min}$ in air atmosphere. The initial sample weight was approximately $8 \mathrm{mg}$.

\subsubsection{Mechanical properties}

Uniaxial tensile tests were carried out at room temperature. The $5 \mathrm{~mm} \times 10 \mathrm{~mm}$ samples were tested to failure at a crosshead speed of $0.5 \mathrm{~mm} / \mathrm{min}$ in a Universal Testing Machine (Shimadzu model AG 1) with an operating load cell of $1 \mathrm{kN}$. The number of samples tested for each membrane was at least three. Prior to the measurements, the membranes were stabilized in distilled water at $50{ }^{\circ} \mathrm{C}$ for $3 \mathrm{~h}$.

\subsubsection{Ionic conductivity}

The conductivity of the membranes was determined by means of electrochemical impedance spectroscopy technique (EIS). The characterization was carried out using a cell constituted by two compartments separated by two $\mathrm{O}$ rings where membrane was sandwiched [22]. The measurements were performed with the membrane samples in contact with aqueous $\mathrm{HCl}$ solutions at different concentrations $\left(4 \times 10{ }^{4} \mathrm{M} \leq c \leq 0.1 \mathrm{M}\right)$ at room tem perature. Before testing, the membranes were immersed for at least $12 \mathrm{~h}$ in a solution of the appropriated $\mathrm{HCl}$ concentration.

The impedance system consisted of a frequency response analyzer (Solartron 1260) and electrochemical interface (Solartron 1287). The measurements were carried out between $10{ }^{1} \mathrm{~Hz}$ and $1 \mathrm{MHz}$ and an oscillating voltage of $10 \mathrm{mV}$. Tests were also performed at different temperatures $\left(3080{ }^{\circ} \mathrm{C}\right.$ ) and for this purpose, a Binder KMF 115(E5.2) temperature chamber was used. In this case, the conductivity was measured after $15 \mathrm{~min}$ of equilibration at each temperature.

The proton conductivity was calculated from the following equation: $\sigma=d / R S$, where $d$ and $S$ are the thickness and the surface area of the sample, respectively. The resistance of the membrane $(R)$ was estimated from the Nyquist plot and considering the corresponding geometric factors.

\section{Results and discussion}

\subsection{Sulfonation degree}

The sulfonation reaction was evaluated by means of ${ }^{1} \mathrm{H}$ NMR spectroscopy. Fig. 1 shows the chemical structure as well as the ${ }^{1} \mathrm{H}$ NMR spectra corresponding to polysulfone (PSU) and sulfo nated polysulfone (sPSU).

The proton resonance in sPSU spectra which appear at $\sim 7.7 \mathrm{ppm}$ was assigned to the proton adjacent to the incorporated acid group $\left(\mathrm{SO}_{3} \mathrm{H}\right)$. Thus, the presence of this peak confirmed the success of the sulfonation process. The sulfonation degree of sPSU was calculated using a modified formula reported elsewhere [23], taking into account that the polysulfone might be sulfonated up to two sulfonic group per monomer unit. Thus, a sulfonation degree of $30 \%$ was obtained.

\subsection{Membrane morphology}

With the aim to study the dispersion of the inorganic particles in the composite membranes, SEM micrographs of the cross section of the studied membranes were obtained. The SEM images and the EDS analysis of the silica doped polysulfone membranes indicated a uniform and homogeneous distribution of inorganic oxide up to $4 \mathrm{wt} \%$ through the polymer matrix (Fig. 2a c). It can be observed that no cavities are present, showing a good adhesion between inorganic particles and the polysulfone. However, for the highest concentration (6 wt\%), the SEM micrographs showed evidence of agglomeration of $\mathrm{SiO}_{2}$ nanoparticles on the bottom surface of the membrane (Fig. 2c). This fact might be related with a silica migration by gravity toward the membrane bottom surface produced during the membrane preparation. On the other hand, the sPSU/SiO $/ 2$ PMoA composite membranes showed uniform dis persion of the inorganic solids throughout the membrane without presence of agglomerates (Fig. 2d).

\subsection{FT IR analysis}

The FTIR spectra of inorganic materials, PSU, sPSU and sPSU/ $\mathrm{SiO}_{2} / \mathrm{PMoA}$ membranes are shown in Fig. 3.

The $\mathrm{SiO}_{2}$ powder showed a characteristic band at $805 \mathrm{~cm}{ }^{1}$ associated to the symmetric Si O Si stretch, at $1090 \mathrm{~cm}^{1}$ and $1220 \mathrm{~cm}{ }^{1}$ corresponding to the asymmetric Si O Si stretch and another one at $960 \mathrm{~cm}^{1}$ characteristic of the $\mathrm{Si} \mathrm{OH}$ stretch (Fig. 3a) [24,25]. On the other hand, the FTIR spectrum of PMoA showed the characteristic bands of this Keggin type heteropolya cid. Thus, the vibration modes at 1065, 960, 869 and $782 \mathrm{~cm}^{1}$ correspond to the asymmetric stretching vibrations of $\mathrm{P} \mathrm{O}$, $\mathrm{Mo}=\mathrm{O}$, Mo $\mathrm{O}_{\mathrm{b}}$ Mo and Mo $\mathrm{O}_{\mathrm{c}}$ Mo, respectively [26 28].

Regarding to the membranes, the spectrum of SPSU (Fig. 3b) showed the characteristic peak at $1024 \mathrm{~cm}^{1}$ which are assigned to the symmetric stretching of the sulfonate group [29]. The presence of this signal, which is not shown on PSU spectrum, confirmed the success of the sulfonation reaction. On the other hand, although the peaks of polysulfone are masking some vibration modes of $\mathrm{SiO}_{2}$ and $\mathrm{PMoA}$, it was possible to observe additional absorption bands associated to these materials on sPSU/ $\mathrm{SiO}_{2} / \mathrm{PMoA}$ composites (Fig. 3b). Also, it can be noticed that the band assigned to the edge shared octahedral of Keggin unit (Mo $\mathrm{O}_{\mathrm{b}} \mathrm{Mo}$ ) at $869 \mathrm{~cm}^{1}$ in pure PMoA, was shifted to higher wavenumber in the doped membrane, around to $907 \mathrm{~cm}{ }^{1}$. This frequency shift was attributed to the interaction of oxygens of PMoA with hydroxyl groups from hydrated oxide structure, which reflects the ability of the silica oxide to retain the PMoA into polymer matrix [27], improving the stability of this material inside the hybrid material. Another consequence of this interaction is the appearance of several and broader bands in the $800900 \mathrm{~cm}^{1}$ range. It is worth to note that the peak at $1024 \mathrm{~cm}{ }^{1}$ of sPSU was slightly shifted to higher wavenumber when the $\mathrm{SiO}_{2}$ were incorporated, indicating weak interactions between the inorganic particles and the sulfonated group, which probably corresponds to hydrogen bonding. This effect was more pronounced with the subsequent addition of heteropolyacid.

\subsection{XRD analysis}

The X Ray diffraction patterns of inorganic powders as well as sPSU and sPSU/SiO $/ 2$ PMoA membranes are illustrated in Fig. 4.

Polysulfone membrane and $\mathrm{SiO}_{2}$ showed a very broad peaks located at $2 \theta=18.5^{\circ}$ and $22^{\circ}$ respectively, typical of very low crystalline materials $[30,26]$. On the other hand, the XRD pattern of pure phosphomolybdic acid showed intense peaks due to its higher crystallinity as reported elsewhere [31]. In the case of sPSU/ $4 \% \mathrm{SiO}_{2} / 10 \% \mathrm{PMoA}$ composite, the shoulder at $26^{\circ}(2 \theta)$ was due to the presence of highly dispersed heteropolyacid into the polymer matrix. On the other hand, the signal associated to $\mathrm{SiO}_{2}$ was 


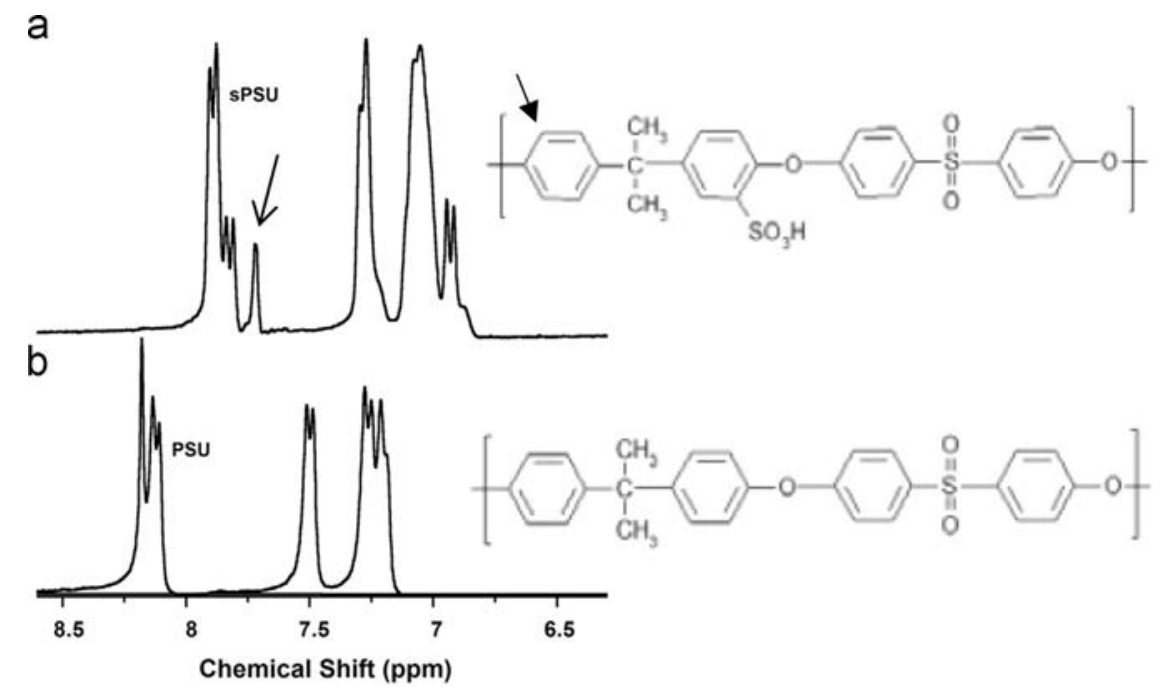

Fig. 1. Chemical structures and H-NMR spectra of polysulfone (PS) and sulfonated polysulfone (sPSU).

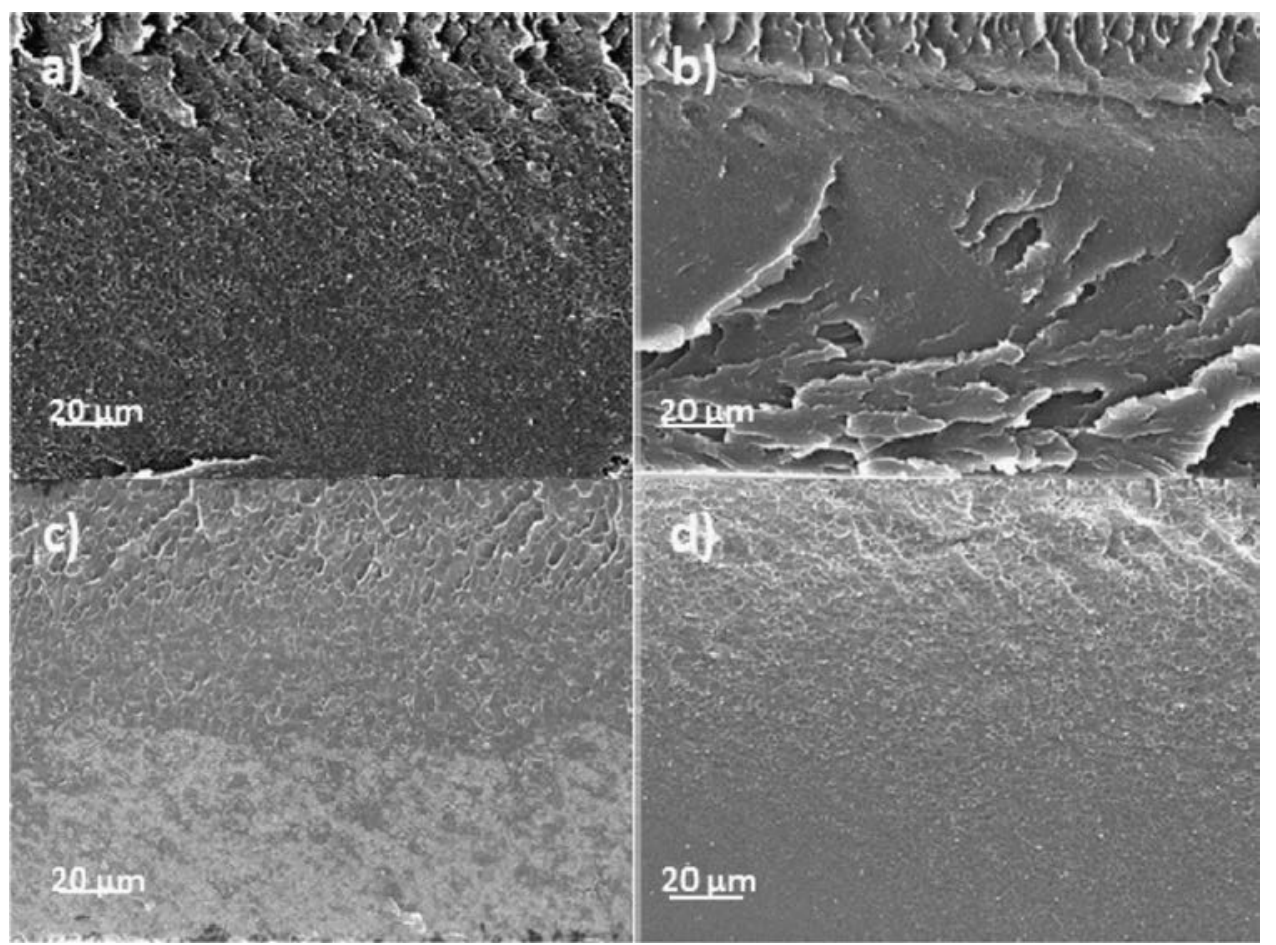

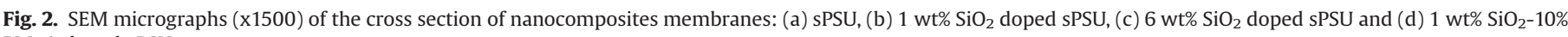
PMoA doped sPSU.

difficult to appreciate due to its amorphous character as well as its low concentration into the composite.

\subsection{Heteropolyacid extraction}

The extracted percentages of PMoA after water treatment from sPSU/10PMoA composites membranes with different silica content are shown in Table 1 . The results showed that, in spite of the potential loss of this heteropolyacid in water, the introduction of silica content up to $1 \mathrm{wt} \%$ leads to PMoA stabilization within polymer backbone. However, this stabilization decreases when $\mathrm{SiO}_{2}$ content is above $2 \mathrm{wt} \%$.

Similar results were reported in the study by Zhang et al. [19], where they observed that $\mathrm{SiO}_{2}$ content below $2 \%$ stabilizes the PWA within the sulfonated polysulfone backbone. In this case the
HPA extracted were lower due to the lower solubility of PWA in water in comparison with that of PMoA.

\subsection{Water uptake}

The obtained values of water uptake percentages for the different studied membranes are shown in Fig. 5. The results showed that the incorporation of the nanoparticles of $\mathrm{SiO}_{2}$ produced an increase of the water absorption in comparation with the pristine sPSU. Similar result has been also reported by other authors using silica gel nanoparticles and it was associated with the hydrophilic nature of the silica due to the presence of $\mathrm{Si} O \mathrm{OH}$ groups in the composite [19] which can form bonding with $\mathrm{H}_{2} \mathrm{O}$ molecules [32]. 
a

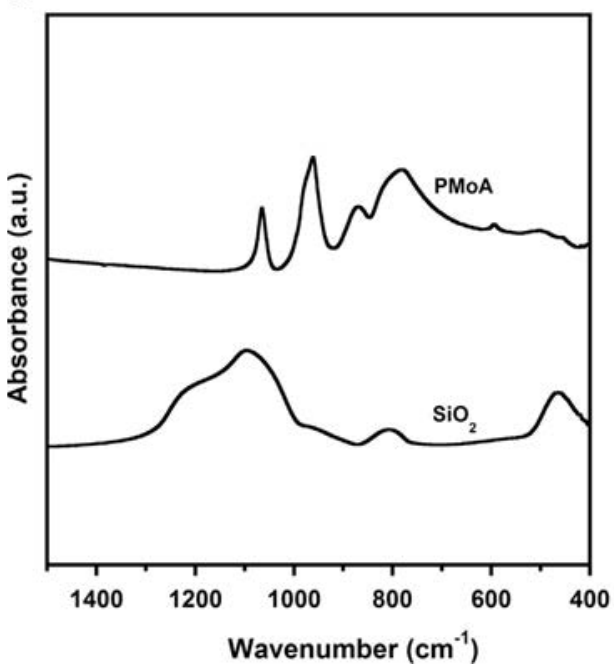

b

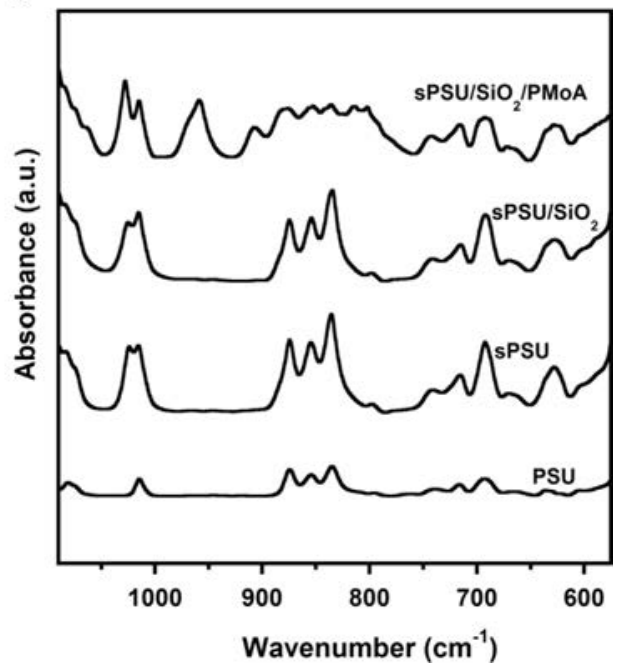

Fig. 3. FTIR spectra of (a) PMoA and $\mathrm{SiO}_{2}$ powders (b) PSU, sPSU and doped sPSU membranes.

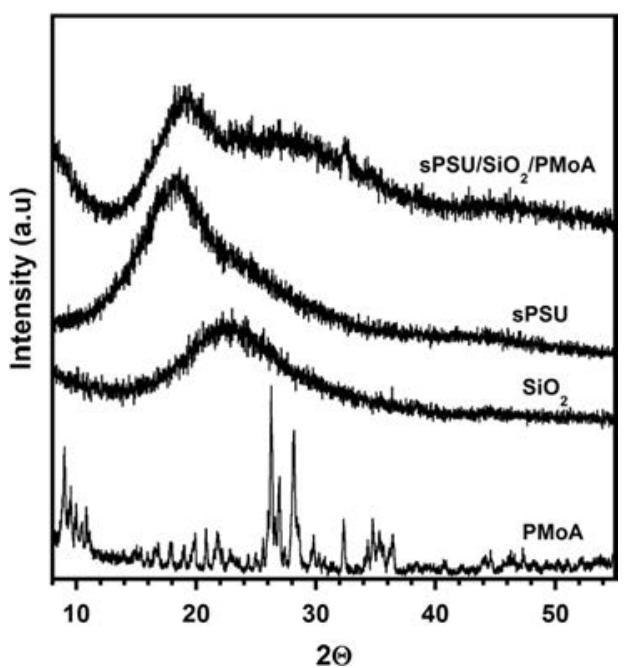

Fig. 4. XRD patterns of inorganic powders and sPSU and $s P S U / 4 \% \mathrm{SiO}_{2} / 10 \% \mathrm{PMoA}$ membranes.

Table 1

PMoA extraction of different sPSU/10PMoA composite membranes in water.

\begin{tabular}{|c|c|c|}
\hline Membrane & $\mathrm{SiO}_{2}$ (\%wt) & PMoA extraction (\%) \\
\hline SPSU/10PMoA & 0 & 18.0 \\
\hline sPSU/0.5SiO ${ }_{2} / 10 \mathrm{PMoA}$ & 0.5 & 9.2 \\
\hline sPSU/1SiO $/ 2 / 10 P M o A$ & 1 & 8.8 \\
\hline sPSU/2SiO $/ 2 / 10 P M o A$ & 2 & 13.2 \\
\hline $\mathrm{sPSU} / 4 \mathrm{SiO}_{2} / 10 \mathrm{PMoA}$ & 4 & 33.1 \\
\hline
\end{tabular}

The water uptake of the composites containing $\mathrm{SiO}_{2} / \mathrm{PMoA}$ particles was lower in comparation with that $\mathrm{SiO}_{2}$ doped mem branes. Similar results were obtained in the study of Smitha et al. [16] with phosphotungstic acid, where the reduction of the water uptake of the polysulfone was attributed to the reduction of water absorption sites due to interactions between the heteropolyacid and the polymer, as demonstrated before in FTIR spectra.

\subsection{Thermal analysis}

Firstly, attention was paid to the thermogravimetric behavior of sPSU/SiO $\mathrm{S}_{2}$ composite membranes. Decomposition curves of all

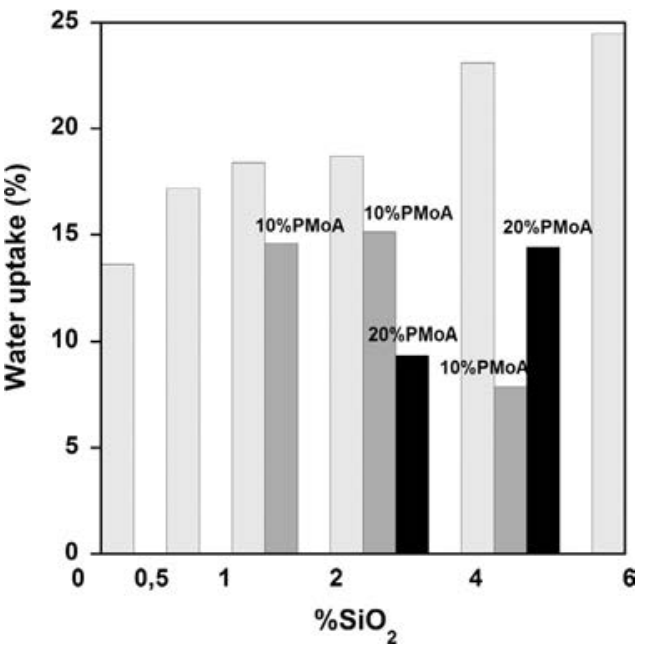

Fig. 5. Water uptake (\%) of sPSU and composites membranes.

studied membranes exhibited the same pattern as is shown in Fig. 6a. The preliminary mass loss produced between $50{ }^{\circ} \mathrm{C}$ and $250{ }^{\circ} \mathrm{C}$, corresponds to the evaporation of free water or desorption of water bonded to the hydrophilic sulfonic groups [33]. After that, in the range of $280450{ }^{\circ} \mathrm{C}$, the sample mass gently decreased due to the desulfonation process, which involves evolution of $\mathrm{SO}_{2}$ and SO gases. The weight loss produced during this temperature range is critical due to its relation with the ion exchange properties of the composites [34]. On the other hand, it can be seen a slight enhancement in thermal stability of these sulfonic acids groups due to the incorporation up to $2 \mathrm{wt} \%$ of $\mathrm{SiO}_{2}$ nanoparticles. Thus, the maximum degradation temperature corresponding to desul fonation process was $332{ }^{\circ} \mathrm{C}$ and $345^{\circ} \mathrm{C}$ for sPSU and sPSU $/ 2 \mathrm{SiO}_{2}$, respectively. The final weight loss, which started at $450{ }^{\circ} \mathrm{C}$, is attributed to the polymer backbone decomposition. In this case, the $\mathrm{SiO}_{2}$ doped membranes with less than $4 \mathrm{wt} \%$ showed higher decomposition temperature due to the presence of the silica nanoparticles. The shift of this temperature can be attributed to the interaction of this inorganic oxide and polysulfone which limits the movements of polymer chain segments.

The $\mathrm{sPSU} / \mathrm{SiO}_{2}$ composite membranes containing inorganic heteropolyacid showed lower weight loss than $\mathrm{sPSU} / \mathrm{SiO}_{2}$ in the temperature range associated to elimination of absorbed water (Fig. 6b). Thus, at $150{ }^{\circ} \mathrm{C}$ a weight loss of $\sim 6 \%, 4 \%$ and $2 \%$ for sPSU 
$2 \% \mathrm{SiO}_{2}, \mathrm{sPSU} / 2 \% \mathrm{SiO}_{2} / 10 \% \mathrm{PMoA}$ and $\mathrm{sPSU} / 2 \% \mathrm{SiO}_{2} / 20 \% \mathrm{PMoA}$ was obtained, respectively. Also, the onset temperature of the decom position of sPSU backbone was lower in the case of sPSU $/ 2 \% \mathrm{SiO}_{2} /$ $20 \% \mathrm{PMoA}$ than the sPSU/SiO ${ }_{2}$, indicating that this inorganic acid can accelerate the degradation of the polymer. Furtado and Gomes [35] showed that the incorporation of tungstophosphoric acid into bisphenol A polysulfone produced an increase of main chain degradation of the polymer. This effect was assigned to the presence of radicals originated from the decomposition of the inorganic acid. Finally, the residual mass above $750{ }^{\circ} \mathrm{C}$ is related to PMoA content. To sum up, all the synthesized membranes showed adequate thermal stability for fuel cell applications at tempera tures below $100{ }^{\circ} \mathrm{C}$.

\subsection{Mechanical properties}

The tensile strength and \% elongation at break of all studied membranes are shown in Table 2.

The sPSU $/ \mathrm{SiO}_{2}$ membranes exhibited higher strength at break than the sulfonated polymer up to $4 \mathrm{wt} \% \mathrm{SiO}_{2}$. This fact shows that $\mathrm{SiO}_{2}$ particles act as reinforcing agents for very low amount of particles and can be related with an interaction between $\mathrm{SiO}_{2}$ and sulfonated matrix which results in the formation of crosslinked network within the polymer matrix. This interaction produces an enhance of the energy of breaking down of the polymer main chains [12]. At the highest concentration, the excessive oxide content produced a weakness of both properties tensile strength and \% elongation of sPSU [19]. This could be related to the heterogeneous microstructure of this membrane.

The decrease on the elongation at break of sPSU at the higher concentrations of $\mathrm{SiO}_{2}$ nanoparticles ( $>2 \mathrm{wt} \%$ ) was related to the brittle nature of the composite due to the incorporation of the filler and the formation of $\mathrm{SiO}_{2}$ nanoparticles clusters which results in a restriction of ductile matrix deformation. These results are in agreement with the studies that show a loss of flexibility of polymer due to the incorporation of inorganic particles [36].

On the other hand, the results showed that the incorporation of PMoA produced a decrease in the tensile strength, being this effect

a

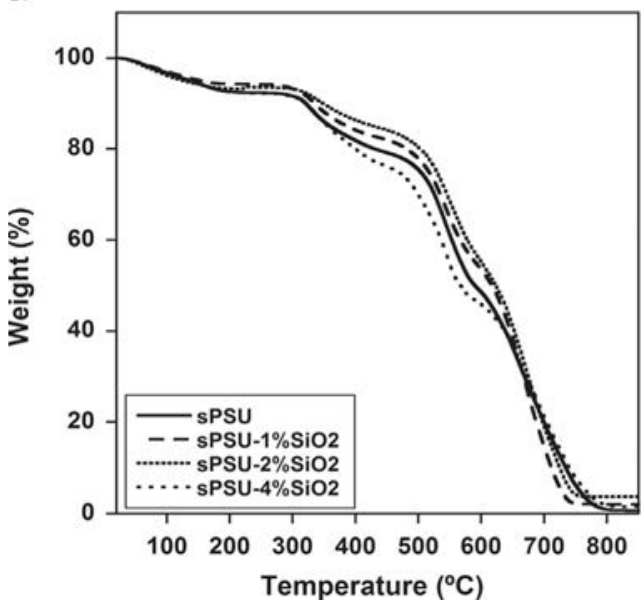

less pronounced at higher $\mathrm{SiO}_{2}$ content. However, sPSU/SiO $/ 20 \%$ PMoA membranes exhibited higher elongation at break in com paration with $\mathrm{sPS} / \mathrm{SiO}_{2}$ composites. Thus, sPSU $/ 4 \% \mathrm{SiO}_{2}$ composites showed around $68 \%$ increase in \% elongation at break due to the addition of 20 wt\% PMoA. In the study performed by Genova et al. [37], tensile test shows an improvement of mechanical properties of phosphatoantimonic acid filled sPSU membranes. However, Smitha et al. [16] observed a reduction in the elongation at break of polysulfone with increasing concentration of phosphotungstic acid ( $>40 \%$ PWA). This difference in the mechanical property might be associated with the heteropolyacid content and the homogeneity of the dispersion.

\subsection{Ionic conductivity}

The electrical characterization of the studied membranes was performed by electrochemical impedance spectroscopy. The resis tance values were obtained from the intercept on the real axis at the high frequency end of the Nyquist plot (Fig. 7a).

All spectra consisted of a semicircle (Fig. 7a), which was associated to the membrane capacitance (or constant phase element of the membrane) acting in parallel with its resistance. The size of this semicircle changes with the $\mathrm{HCl}$ concentration of the solution. Also, the fact that semicircle did not intercept the origin of the graph, showed the existence of a resistive element which should be related to the electrolyte solution. The experi mental data of the studied membranes were fitted to different equivalent circuits, obtaining the best fit to that shown in the inset of Fig. $7 \mathrm{a} . R_{1}$ is associated with the resistance of the electrolyte solution and the distance between electrodes, $R_{2}$ represents the ionic resistance of the membrane and CPE is assigned to the geometric capacitance of the membrane.

As expected, the resistivity associated to the membrane decreased as $\mathrm{HCl}$ concentration increased in all studied concentra tion range (Fig. 7b) showing a possible dependence of this parameter with the electrolyte solution embedded in the polymer matrix [30]. This behavior was observed in all membranes of this study.

b

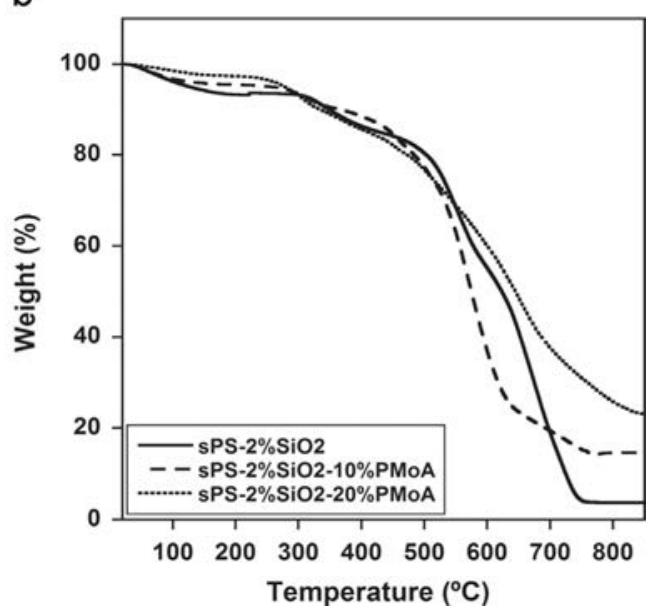

Fig. 6. Decomposition curves of (a) silica doped sulfonated polysulfone and (b) $\mathrm{SiO}_{2} / \mathrm{PMoA}$ sulfonated polysulfone.

Table 2

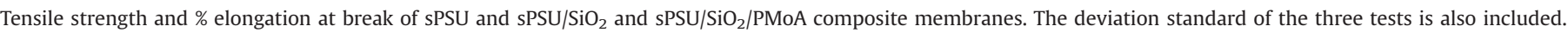

\begin{tabular}{|c|c|c|c|c|c|c|c|c|}
\hline Membrane & sPSU & $2 \mathrm{SiO}_{2}$ & $4 \mathrm{SiO}_{2}$ & $6 \mathrm{SiO}_{2}$ & $2 \mathrm{SiO}_{2} / 10 \mathrm{PMoA}$ & $2 \mathrm{SiO}_{2} / 20 \mathrm{PMoA}$ & $4 \mathrm{SiO}_{2} / 10 \mathrm{PMoA}$ & $4 \mathrm{SiO}_{2} / 20 \mathrm{PMoA}$ \\
\hline Tensile Strength (MPa) & $26.5 \pm 4.8$ & $41.7 \pm 6.2$ & $31.6 \pm 3.9$ & $18 \pm 2$ & $25.2 \pm 1.6$ & $21.0 \pm 2.1$ & $21.6 \pm 5.0$ & $26.9 \pm 0.7$ \\
\hline Elongation at break (\%) & $18.8 \pm 4.5$ & $21.9 \pm 1.3$ & $15.7 \pm 3.3$ & $9.2 \pm 0.2$ & $20.2 \pm 6.0$ & $24.8 \pm 2.8$ & $12.7 \pm 1.7$ & $26 \pm 4$ \\
\hline
\end{tabular}


a

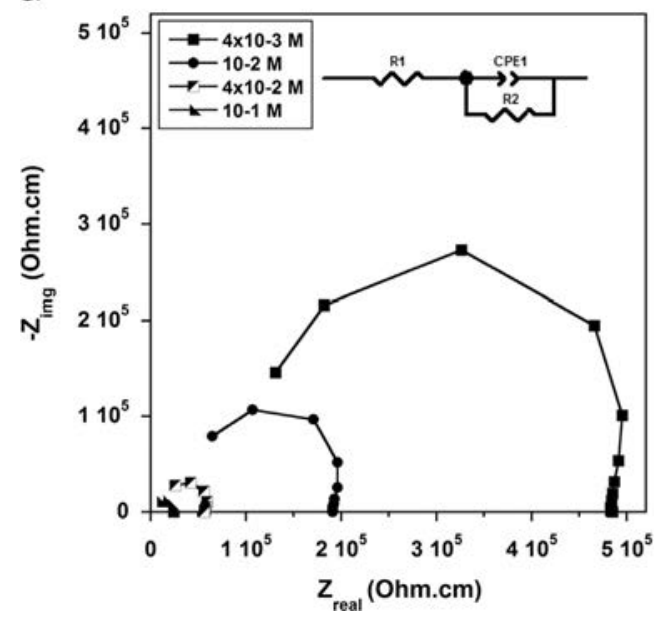

b

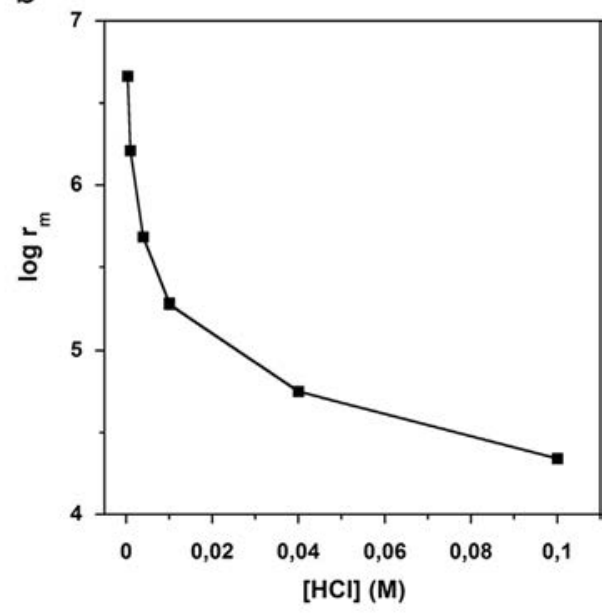

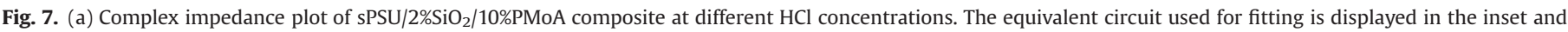
(b) ionic resistivity of this membrane for different $\mathrm{HCl}$ solutions.

The conductivity of sPSU and different $\mathrm{sPSU} / \mathrm{SiO}_{2}$ composite membranes measured at room temperature is shown in Fig. 8. All membranes showed conductivity values of the same order of magnitude than Nafion $\left(1.36 \times 10^{6}\right.$ and $2.09 \times 10^{6} \mathrm{~S} / \mathrm{cm}$ for Nafion 112 and sPSU, respectively), which has been taken as reference.

The results pointed out that the sPSU/SiO ${ }_{2}$ membranes slightly improved their ionic conductivity as the amount of $\mathrm{SiO}_{2}$ increases up to $4 \mathrm{wt} \%$ (Fig. 8). This fact has been related with the hydrophilic nature of silica nanoparticles and the ability of this material to retain water even at high temperature as reported elsewhere [36]. The decrease on the conductivity for the highest values of $\mathrm{SiO}_{2}$, may be related to the high heterogeneity of this membrane, where the most of the $\mathrm{SiO}_{2}$ was accumulated on one side of the membrane (see Fig. 2d).

On the other hand, the incorporation of the heteropolyacid produced a decreased of the conductivity of $\mathrm{sPSU} / \mathrm{SiO}_{2}$ membranes at room temperature (Table 3 ). This fact can be correlated with the decrease of the water uptake observed previously (Fig. 5).

However, a different trend was observed when the temperature was increased. The proton conductivity values of $\mathrm{sPSU} / \mathrm{SiO}_{2} / \mathrm{PMoA}$ were close or even greater than $s P S U / S i O_{2}$ membranes at high temperature range (Fig. 9). Thus, for a concentration of $2 \mathrm{wt} \% \mathrm{SiO}_{2}$, the incorporation of $10 \%$ PMoA showed similar conductivity than PMoA free composite at $80{ }^{\circ} \mathrm{C}$ (Fig. 9a). Furthermore, when the concentration of PMoA is increased to $20 \mathrm{wt} \%$, the conductivity of the $\mathrm{sPSU} / 2 \mathrm{SiO}_{2} / \mathrm{PMoA}$ composite becomes higher in comparison with the $\mathrm{SiO}_{2}$ doped membrane above $50{ }^{\circ} \mathrm{C}$. This increase of the conductivity showed for the composites is the results of synergic effect, that is, the higher water uptake provided for the silica oxide as well as acidity of the heteropolyacid particles. A similar behavior was observed for the sPSU/SiO $/ 2 / \mathrm{PMoA}$ composites with $4 \mathrm{wt} \% \mathrm{SiO}_{2}$ (Fig. 9b). These results are in the line of the obtained by Zhao [19], where it was observed that the proton conductivity of Nafion/silicon oxide/PWA composite membranes was lower that Nafion membrane at low temperatures and found to be higher to that the Nafion and Nafion/ $/ \mathrm{SiO}_{2}$ at high temperatures.

The activation energies of sPSU, sPSU $/ \mathrm{SiO}_{2}$ and $\mathrm{sPSU} / \mathrm{SiO}_{2} / \mathrm{PMoA}$ were calculated from the linear fitting of data of Fig. 9 (Arrhenius plot). The obtained values were 9.1, 11.8, 16.6 and $20.7 \mathrm{~kJ} / \mathrm{mol}$ corresponding to sPSU/2 wt $\% \mathrm{SiO}_{2}$, sPSU/4 wt\% $\mathrm{SiO}_{2}$, sPSU/2 wt\% $\mathrm{SiO}_{2} / 10 \% \mathrm{PMo}$ a and $\mathrm{sPSU} / 2 \mathrm{wt} \% \mathrm{SiO}_{2} / 20 \% \mathrm{PMoA}$, respectively. The low values obtained for the activation energies pointed that the predominant mechanism of proton transport in the studied

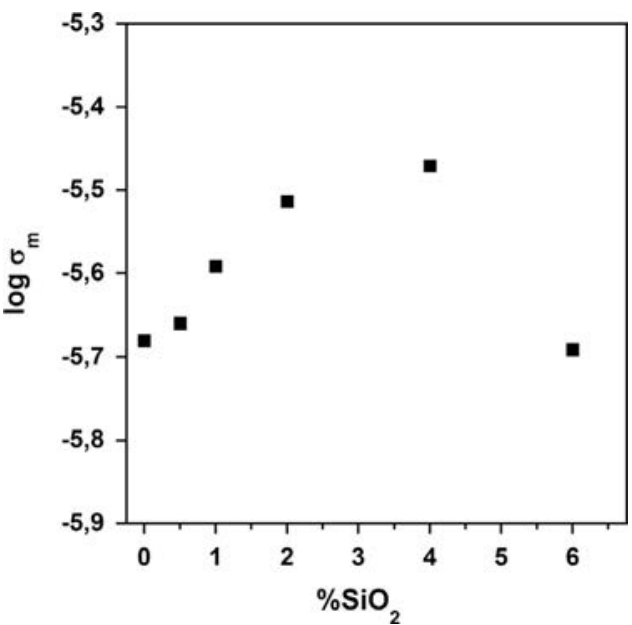

Fig. 8. Ionic conductivity of $s P S U$ and $s P S U / \mathrm{SiO}_{2}$ membranes measured at room temperature $\left([\mathrm{HCl}] \quad 4 \times 10{ }^{3} \mathrm{M}\right)$.

Table 3

Ionic conductivity obtained for $\mathrm{sPSU} / \mathrm{SiO}_{2} / \mathrm{PMoA}$ hybrid membranes measured at room temperature ([HCl] $4 \times 10{ }^{3} \mathrm{M}$ ).

\begin{tabular}{lllllll}
\hline Membrane & $\mathbf{1 S i O}_{2}$ & $\begin{array}{l}\mathbf{1 S i O}_{2} / \\
10 \mathrm{PMoA}\end{array}$ & $\mathbf{2 S i O}_{2}$ & $\begin{array}{l}2 \mathrm{SiO}_{2} / \\
10 \mathrm{PMoA}\end{array}$ & $\begin{array}{l}\mathbf{2 S i O}_{2} / \\
20 \mathrm{PMoA}\end{array}$ & $\begin{array}{l}4 \mathrm{SiO}_{2} / \\
\mathbf{1 0 P M o A}\end{array}$ \\
\hline $\mathbf{1 0}^{\mathbf{6}} \times \sigma_{\boldsymbol{m}}\left(\mathrm{S} \mathrm{cm}^{\mathbf{1}}\right)$ & 2.56 & 1.76 & 3.06 & 1.67 & 2.15 & 2.06 \\
\hline
\end{tabular}

membranes was the vehicular mechanism [38]. The higher activa tion energies obtained for the composites membranes in compar ison with the neat polysulfone could be attributed to a change on the proton transport mechanism.

\section{Conclusions}

In this study, $\mathrm{SiO}_{2}$ and $\mathrm{PMoA}$ were used as proton inorganic additives to prepare polysulfone nanocomposites as possible polymer electrolytes for fuel cells. The composites were prepared using solvent casting technique. The presence of inorganic parti cles into the polymer as well as the interactions between them and 
a

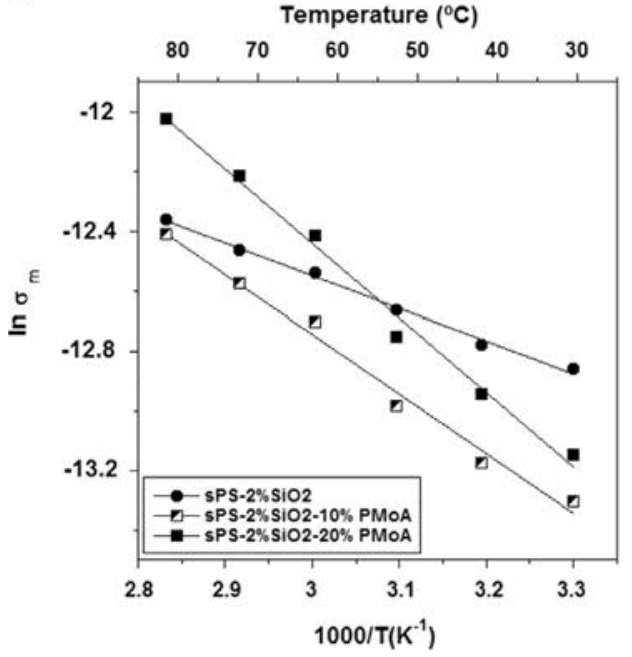

b

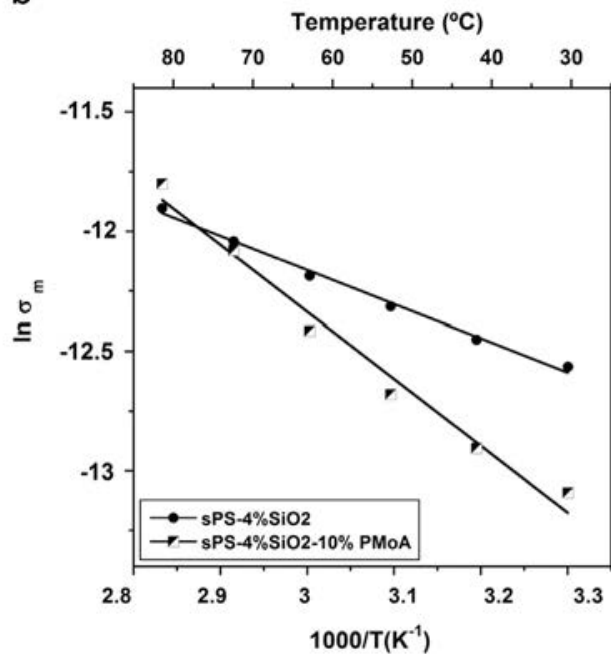

Fig. 9. Arrhenius plot for proton conductivity corresponding to $\mathrm{sPSU} / \mathrm{SiO}_{2}$ membranes and sPSU/SiO $/ 2 / \mathrm{PMoA}$ composites.

the sulfonated polysulfone were confirmed by SEM, FTIR spectro scopy and XRD. In addition, interactions between the inorganic particles resulted in the retention of the heteropolyacid in the polymer matrix.

In general, the incorporation of inorganic material produced a decrease of both, the tensile strength and \% elongation at break of the composite membranes. However, the addition of 20\% PMoA improved the ductile behavior of the composites for both studied sPSU/ $\mathrm{SiO}_{2}$ membranes. Also, the results pointed that the synthe sized hybrid membranes show good thermal stability at tempera tures up to $200{ }^{\circ} \mathrm{C}$. On the other hand, the electrochemical study showed that the conductivity value at room temperature of sPSU was improved with the incorporation of $\mathrm{SiO}_{2}$ nanoparticles, while sPSU/SiO $/$ PMoA composites showed lower conductivity than $\mathrm{SiO}_{2}$ doped membranes at room temperature. However, at higher temperatures the conductivity of these nanocomposites increased showing higher values than those observed for $\mathrm{sPSU} / \mathrm{SiO}_{2}$ mem branes. This increase was more appreciable when the amount of PMoA increased from $10 \%$ to $20 \%$, and can be attributed to the surface functional sites for proton transfer provided by PMoA particles. Finally, the results of the present study show that the hybrid membrane with $2 \% \mathrm{SiO}_{2}$ and $20 \% \mathrm{PMoA}$ seems to be a promising candidate for application in PEMFCs operated at high temperature.

\section{Acknowledgments}

This work has been supported by the Projects from the Regional government (Comunidad de Madrid through MATERYE NER3CM S2013/MIT 2753) and MINECO (MAT2013 46452 C4 3R) from Spanish Government.

\section{References}

[1] K. Agbossou, M.L. Kolhe, J. Hamelin, É. Bernier, T.K. Bose, Electrolytic hydrogen based renewable energy system with oxygen recovery and re-utilization, Renew. Energy 29 (2004) 1305-1318.

[2] I. Honma, H. Nakajima, S. Nomura, High temperature proton conducting hybrid polymer electrolyte membranes, Solid State Ion. 154 (2004) 707-712.

[3] S.H. Chan, M. Han, S.P. Jiang, Guidelines for stable operation of a polymer electrolyte fuel cell with self-humidifying membrane electrolyte assembly, J. Electrochem. Soc. 154 (2007) 486-493.

[4] W. Guo, X. Li, H. Wang, J. Pang, G. Wang, Z. Jiang, S. Zhang, Synthesis of branched sulfonated poly(aryl ether ketone) copolymers and their proton exchange membrane properties, J. Membr. Sci. 444 (2013) 259-267.
[5] F. Göktepe, A. Bozkurt, Ş.T. Günday, Synthesis and proton conductivity of poly (styrene sulfonic acid)/heterocycle-based membranes, Polym. Int. 57 (2008) 133-138.

[6] P. Staiti, M. Minutoli, Influence of composition and acid treatment on proton conduction of composite polybenzimidazole membranes, J. Power Sources (2001) 9-13.

[7] F. Lufrano, G. Squadrito, A. Patti, E. Passalacqua, Sulfonated polysulfone as promising membranes for polymer electrolyte fuel cells, J. Appl. Polym. Sci. 77 (2000) 1250-1257.

[8] M.L. Di Vona, D. Marani, A. D’Epifanio, E. Traversa, M. Trombetta, S. Licoccia, A covalent organic/inorganic hybrid proton exchange polymeric membranes: synthesis and characterization, Polymer 46 (2005) 1754-1758.

[9] R.K. Nagarle, G.S. Gohil, V.K. Shahi, R. Rangarajan, Organic-inorganic hybrid membranes: thermally stable cation-exchange membrane prepared by the sol-gel method, Macromolecules 37 (2004) 10023-10030.

[10] C. Klaysom, S. Moon, B. Ladewig, G. Lu, L. Wang, The effects of aspect ratio of inorganic fillers on the structure and property of composite ion-exchange membranes, J. Colloid Interface Sci. 363 (2011) 431-439.

[11] Yu-Huei Sua, Ying-Ling Liua, Yi-Ming Suna, Juin-Yih Laia, Da-Ming Wanga, Yan Gaoe, Baijun Liue, Michael D. Guivere, Proton exchange membranes modified with sulfonated silica nanoparticles for direct methanol fuel cells, J. Membr. Sci. 296 (2007) 21-28.

[12] Jing-Feng Li, Zhen-Liang Xua, Hu Yanga, Li-Yun Yua, Min Liua, Effect of $\mathrm{TiO}_{2}$ nanoparticles on the surface morphology and performance of microporous PES membrane, Appl. Surf. Sci. 255 (2009) 4725-4732.

[13] B. Libby, W.H. Smyrl, E.L. Cussler, Polymer-zeolite composite membranes for direct methanol fuel cells, AIChE J. 49 (2003) 991-1001.

[14] L. Oingfeng., H. Ronghuan, J.O. Jensen, J.B. Niels, Approaches and recent development of polymer electrolyte membranes for fuel cells operating above $100{ }^{\circ} \mathrm{C}$, Chem. Mater. 15 (2003) 4896-4915.

[15] L. Li, Y.X. Wang, Proton conducting composite membranes from sulfonated polyethersulfone Cardo and phosphotungstic acid for fuel cell application, J. Power Sources (2006) 541-546.

[16] B. Smitha, S. Sridhar, A.A. Khan, Proton conducting composite membranes from polysulfone and heteropolyacid for fuel cell applications, J. Polym. Sci. Part B: Polym. Phys. 43 (2005) 1538-1547.

[17] K.D. Kreuer, Proton conductivity: materials and applications, Chem. Mater. 8 (1996) 610-641.

[18] P. Staiti, A.S. Arico, V. Baglio, F. Lufrano, E. Passalacqua, V. Antonucci, Hybrid Nafion-silica membranes doped with heteropolyacids for application in direct methanol fuel cells, Solid State Ion. 145 (2001) 101-107.

[19] J. Zhang, G. Fei, Y. Liang, Y. Zhang, J.Z.G. Zhao, Influence of silica content in sulfonated polysulfone/ phosphotungstic acid hybrid membranes on properties for fuel cell application, E-polymers 10 (2010).

[20] S.Y. Chao, D.R. Kelsey, Process for preparing sulfonated poly(arylether)resins, United States Patent US 4625000, 1996.

[21] A. Noshay, L.M. Robeson, Sulfonated polysulfone, J. Appl. Polym. Sci. 20 (1976) 1885.

[22] J. Benavente, A. Cañas, M.J. Ariza, A.E. Lozano, J. de Abajo, Electrochemical parameters of sulfonated poly(ether ether sulfone) membranes in $\mathrm{HCl}$ solutions determined by impedance spectroscopy and membrane potential measurements, Solid State Ion. 145 (2001) 53-60.

[23] C. Iojoiu, P. Genova-Dimitrova, M. Marechal, J.-Y. Sanchez, Chemical and physicochemical characterization of ionomers, Electrochim. Acta 51 (2006) 4789 . 
[24] J. Mosa, G. Larramona, A. Durán, M. Aparicio, Synthesis and characterization of $\mathrm{P}_{2} \mathrm{O}_{5}-\mathrm{ZrO}_{2}-\mathrm{SiO}_{2}$ membranes doped with tungstophosphoric acid (PWA) for applications in PEMFC, J. Membr. Sci. 307 (2008) 21-27.

[25] R. Padmavathi, R. Karthikumar, D. Sangeetha, Multilayered sulphonated polysulfone/silica composite membranes for fuel cell applications, Electrochim. Acta 71 (2012) 283-293.

[26] Z. Cui, W. Xing, Ch. Liu, J. Liao, H. Zhang, Chitosan/heteropolyacid composite membranes for direct methanol fuel cell, J. Power Sources 188 (2009) 24-29.

[27] Z. Shao, P. Joghee, I. Hsing, Preparation and characterization of hybrid Nafionsilica membrane doped with phosphotungstic acid for high temperature operation of proton exchange membrane fuel cells, J. Membr. Sci. 229 (2004) 43-51.

[28] C. Rocchiccioli-Deltcheff, M. Fournier, R. Franck, R. Thouvenot, Vibrational investigations of polyoxometalates. 2. Evidence for anion-anion interactions in molybdenum(VI) and tungsten(VI) compounds related to the Keggin structure, Inorg. Chem. 22 (1983) 207-216.

[29] Y. Devrim, S. Erkan, N. Bac, I. Eroglu, Preparation and characterization of sulfonated polysulfone/titanium dioxide composite membranes for proton exchange membrane fuel cells, Int. J. Hydrog. Energy 34 (2009) 3467-3475.

[30] M.I. Ahmad, S.M. Javaid Zaidi, S. Ahmed, Proton conducting composites of heteropolyacids loaded onto MCM-41, J. Power Sources 157 (2006) 35-44.

[31] Y. Yang, H. Zhang, P. Wang, Q. Zheng, J. Li, The influence of nano-sized $\mathrm{TiO}_{2}$ fillers on the morphologies and properties of PSF UF membrane, J. Membr. Sci. 288 (2007) 231-238.
[32] H.P. Cheng, R.N. Barnett, U. Landman, Structure, collective hydrogen transfer and formation of $\mathrm{Si}(\mathrm{OH})_{4}$ in $\mathrm{SiO}_{2}-\left(\mathrm{H}_{2} \mathrm{O}\right)_{n}$ clusters, J. Chem. Phys. 116 (2002) 9300-9304.

[33] F. Lufrano, V. Baglio, O. Di Blasi, P. Staiti, V. Antonucci, A.S. Aricò, Solid polymer electrolyte based on sulfonated polysulfone membranes and acidic silica for direct methanol fuel cells, Solid State Ion. 216 (2012) 90-94.

[34] Q. Deng, C.A. Wilkie, R.B. Moore, K.A. Mauritz, TGA e FTIR investigation of the thermal degradation of Nafion and Nafion/[silicon oxide]-based nanocomposites, Polymer 39 (1998) 5961-5972.

[35] A.A.M. Furtado, A.S. Gomes, Sulfonated bisphenol-A-polysulfone based composite PEMs containing tungstophosphoric acid and modified by electron beam irradiation, Int. J. Hydrog. Energy 37 (2012) 6228-6235.

[36] P.L. Shao, K.A. Mauritz, R.B. Moore, [Perfluorosulfonate ionomer]/[ $\left.\mathrm{SiO}_{2}-\mathrm{TiO}_{2}\right]$ nanocomposite via polymer in situ sol-gel chemistry sequential alcoxide procedure, J, Polym. Sci. Phys. 34 (1996) 873.

[37] P. Genova-Dimitrova, B. Baradie, D. Foscallo, C. Poinsignon, J.Y. Sanchez, Ionomeric membranes for proton exchange membrane fuel cell (PEMFC): sulfonated polysulfone associated with phosphatoantimonic acid, J. Membr. Sci. 185 (2001) 59-71.

[38] L. Yongli, Q.T. Nguyen, P. Schaetzel, C. Lixon-Buquet, L. Colasse, V. Ratieuville, S. Marais, Proton exchange membranes from sulfonated polyetheretherketone and sulfonated polyethersulfone-cardo blends: Conductivity, water sorption and permeation properties, Electrochim. Acta 111 (2013) 419-433. 